NBER WORKING PAPER SERIES

\title{
INFLATION, REAL INTERE'ST, AND THE DETERMINACY OF EQUILIBRIUM IN AN OPTIMIZING FRAMEWORK
}

Maurice Obstfeld

Working Paper No. $\underline{723}$

\section{NATIONAL BUREAU OF ECOINOMIC RESEARCH 1050 Massachusetts Avenue Cambridge MA 02138}

JuIy 1981

The research reported here is part of the NBER's research program in International Studies. Any opinions expressed are those of the author and not those of the National Bureau of Economic Research. 
Inflation, Real Interest, and the Determinacy of Equilibrium in an Optimizing Framework

Abstract

This paper examines the short-run relation between anticipated inflation and the real rate of interest in a model where agents with perfect foresight maximize utility over infinite lifetimes. In addition to deriving behavioral functions from explicit intertemporal optimization, the approach taken here departs from the usual IS-IM analysis in that it is dynamic and deals with a small economy open to trade in consumption goods. Because capital mobility must be ruled out to allow scope for variation in the real interest rate, the results obtained here for one of the two exchangerate regimes considered--free floating--apply equally to a closed economy. The paper shows that an increase in the expected inflation rate depresses the real. interest rate in the short run when the exchange rate is instantaneously fixed by the central bank. When equilibrium is determinate in the floating-rate case, the real interest rate is invariant with respect to inflation.

\author{
Maurice Cbstfeld \\ Department of Economics \\ International Affairs Building \\ Columbia University \\ New York, NY 10027
}

(212) $280-4190$ 


\section{Introduction}

Working in the context of Metzler's (1951) IS-IM model, Mundell (1963) established a short-run negative relationship between the expected inflation rate and the real rate of interest. According to Mundell's analysis, an increase in the expected inflation rate that left the real interest rate unchanged would reduce desired real money holdings and occasion an excess supply of goods through the wealth-spending channel. Thus, only a decline in real interest, coupled with a rise in nominal interest, could be consistent with simultaneous equilibrium in both the goods and money markets.

This paper examines the validity of Mundell's prediction in a model where agents with perfect foresight maximize utility over infinite life-times. In addition to deriving behavioral functions from explicit intertemporal optimization, the approach taken here departs from Mundell's in two respects. First, the model employed is dynamic and accounts for both the impact and long-run effects of changes in inflation. Second, the model describes a small economy open to trade in consumption goods. Because capital mobility must be ruled out to allow scope for variation in the real interest rate, the results obtained below for one of the two exchange-rate regimes we consider -- free floating -- apply equally to the closed-economy version of the model.

No model can admit the Mundell effect unless it also admits variation in the relative price of physical assets and consumption goods. In this paper, we adopt the extreme assumption that the sole physical asset is capital, I am grateful for discussions with Guillermo Calvo. Financial support provided under National Science Foundation Grant No. SES-8023081 is acknowledged with thanks. 
available to the economy in a fixed supply which may not be augmented through investment. The floating and fixed exchange rate variants of the model we study differ respectively from the models studied by Brock (1975) and Calvo (1981) only in the introduction of non-depreciating, non-reproducible capital. The extension does not remove the multiplicity of convergent perfect-foresight equilibria that may exist in the floating-rate model, even when consumption and real balances are normal goods, when the marginal utility of consumption declines with real balances. 1 This stands in contrast to Fischer's (1979) result that in the Sidrauski (1967) one-sector model with capital and accumulation, normality of both goods ensures a unique convergent perfect-foresight equilibrium.

The paper shows that the Mundell effect is present when the exchange rate is instantaneousiy fixed by the central bank. When equilibrium is determinate in the floating-rate case, there is no Mundell effect. Only in the fixed-rate case does the real return on productive non-money assets fall temporarily in response to an increase in the expected inflation rate. In the alternative case, in which the economy is effectively closed, increased inflation, if it has a determinate effect, causes an immediate fall in desired real balances, but leaves other real magnitudes unchanged.

The organization of the paper is as follows. Section 2 describes the typical household's maximization problem. Section 3 describes perfect-foresight equilibrium under a floating exchange rate, showing that there are plausible circumstances in which there exist convergent perfect-foresight paths other than the stationary-state path. Section 4 assumes that the exchange rate is instantaneously fixed, but is caused by the central bak to depreciate according to a pre-announced schedule. In this setting, an increase in the expected inflation rate is shown to lead

I This type of non-uniqueness for economies lacking capital has been noted in unpublished portions of Brock (1972) and Calvo (1981). ApparentIy, the phenomenon is not widely appreciated. 
to a short-run decline in the real interest rate if the economy is initially at rest. Section 5 summarizes and concludes.

\section{The Household's Problem}

The model is one in which identical households maximize the discounted sum of future instantaneous utilities over an infinite planning horizon. There exists a single, composite consumption good which is perishable and available in fixed supply. The representative household's instantaneous utility is a strictly concave function $u\left(c_{t}, m_{t}\right)$ of its consumption $\left(c_{t}\right)$ and real money holdings $\left(m_{t}\right)$, defined as nominal money holdings $\left(M_{t}\right)$ deflated by the domestic-currency price of output $\left(P_{t}\right)$. The household's objective is to maximize the functional

$$
\int^{\infty} u\left(c_{t}, m_{t}\right) e^{-\delta t} d t
$$

where $\delta$ is a fixed subjective rate of discount. Both consumption and real money services are normal goods. 2

Each household is endowed with a fixed income stream of $y$ units of output, and may hold its remaining wealth either as money or as a non-depreciating, non-produced physical asset ("capital") yielding a fixed return $r$ per unit. ${ }^{3}$ There are $\bar{k}$ units of capital available to the economy, and the price of capital in terms of the consumption

\footnotetext{
2Naturally, $u_{c}, u_{m}>0$. To exclude corner solutions, we assume that $\lim _{c \rightarrow 0} u_{c}(c, m)=\lim _{m \rightarrow 0} u_{m}(c, m)=\infty$.

3 The non-money asset may also be thought of as land (as in Calvo (1979)) or as the foreign currency asset held in an economy with a two-tier exchange-rate system (as in Cumby (1979)).
} 
good is denoted by $q$. We define the real rate of interest as

$$
\frac{r+\dot{q}}{q}
$$

that is, as the sum of the rate of physical return on capital and the expected rate of capital gain. The behavior of this variable is the focus of the analysis below.

Given an initial level of real marketable wealth $w_{0}$, the household maximizes (I) subject to the stock constraint relating marketable wealth $\left(w_{t}\right)$ to holdings of the two assets and the flow constraint linking changes in $w_{t}$ to saving. The stock constraint is written as

$$
w_{t}=m_{t}+q_{t} k_{t}
$$

where $k_{t}$ denotes the number of units of the non-money asset held by the household at time $t$, and $q_{t}$ the expected price of one such unit in terms of consumption. The flow constraint has the form

$$
\dot{w}_{t}=y+r k_{t}+\tau_{t}+\dot{q}_{t} k_{t}+\left(1 / \dot{P}_{t}\right) M_{t}-c_{t}
$$

where $\tau_{t}$ denotes expected real transfer payments from the government. The fourth and fifth terms on the right-hand side of (3) sum to expected real capital gains on the household's financial assets. 4

The maximum principle provides necessary conditions for the maxmization of (1) subject to (2) and (3). 5 First, an optimal program must choose $c_{t}{ }^{\prime} m_{t}$, and $k_{t}$ so as to maximize the current-value Hamiltonian

\footnotetext{
${ }^{4}$ Constraint (3) is consistent with the two-tier exchange market interpretation of the model, since interest earnings on foreign-currency assets are current payments typically repatriated at the commercial exchange rate.

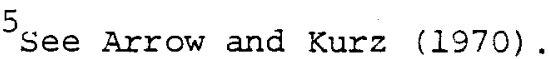




$$
\begin{aligned}
H\left(c_{t^{\prime}} m_{t}{ }^{\prime} k_{t}{ }^{\prime} w_{t}\right)= & u\left(c_{t}{ }^{\prime m_{t}}\right)+\lambda_{t}\left[y+r k_{t}+\tau_{t}+\dot{q}_{t} k_{t}-\left(\dot{p}_{t} / p_{t}\right) m_{t}-c_{t}\right] \\
& +\mu_{t}\left[w_{t}-m_{t}-q_{t} k_{t}\right]
\end{aligned}
$$

In (4), $\lambda_{t}$ is the costate variable, interpreted as the shadow price of saving in utility terms, and $\mu_{t}$ is a Lagrange multiplier. Second, the costate variable must evolve according to the law

$$
\dot{\lambda}_{t}=\delta \lambda_{t}-\frac{\partial H_{t}}{\partial w_{t}}=\delta \lambda_{t}-\mu_{t} .
$$

The first-order conditions for an interior maximum of (4) are

$$
\begin{aligned}
& u_{c}-\lambda=0, \\
& u_{m}-\lambda(\dot{p} / p)-\mu=0, \\
& \lambda(r+\dot{q})-\mu q=0 .
\end{aligned}
$$

(Time subscripts are, for convenience, omitted.) Together, (6) and (7) imply the usual equality between the marginal rate of substitution $\mathrm{u}_{\mathrm{m}} / \mathrm{u}_{\mathrm{c}}$ and the nominal interest rate,

$$
u_{m} / u_{c}=(r+\dot{q}) / q+\dot{p} / p
$$

Combining (5) and (8), we find that

$$
\dot{\lambda} / \lambda=\delta-(r+\dot{q}) / q \text {. }
$$

Along an optimal path, the subjective rate of time preference, $\delta$, must at all times equal the sum of the real interest rate and the percentage increase in the utility shadow price of real wealth. 


\section{Perfect-Foresight Equilibrium with a Floating Exchange Rate}

The conditions derived in the previous section describe how households must choose their consumption and asset demands at each instant, given $\mathrm{w}_{0}$ and expected future paths for government transfers, the price level, and the real price of the non-money asset. They do not ensure optimality from the household's standpoint, however, for the initial shadow price of wealth, $\lambda_{0}$, must be correctly chosen. In this section we assume a freely floating exchange rate, and derive the set of perfect-foresight paths for $m_{t}$ and $q_{t}$ which satisfy both the necessary conditions of optimality and the consistency requirement that the expected and realized values of variables coincide. Associated with each such path is an implied value of $\lambda_{0}$ which may be "wrong" from the household's standpoint, leading to a suboptimal lifetime program given expectations. We therefore focus on paths converging to a stationary state, which are necessarily equilibrium paths. A key finding of this section is that there are plausible circumstances under which there exists a continuum of convergent paths, so that equilibrium prices are indeterminate. When this is not the case and equilibrium prices are determinate, there is no Mundell effect: inflation does not influence the real interest rate.

To derive the system of possible equilibrium paths, some assumptions about the government's behavior are necessary. We assume that government expenditure consists exclusively of transfer payments to the public, and that these are financed entirely by domestic credit creation. The level of transfers is varied so as to maintain a constant (positive) rate of nominal money-supply growth, $\mu$. The implied government budget constraint is: 


$$
\tau_{t}=\mu m_{t}
$$

Taking the number of households to be 1, we define perfect-foresight equilibrium as follows. Let $\left\{\tilde{\mathrm{P}}_{t}\right\}$ be a differentiable path for the price level and $\left\{\tilde{q}_{t}\right\}$ a differentiable path for the price of the non-money asset. Suppose that the household takes as given the paths $\left\{\tilde{p}_{t}\right\},\left\{\tilde{q}_{t}\right\}$, and $\left\{\tilde{\tau}_{t}\right\}=\left\{\mu \mathrm{e}^{\mu t} \mathrm{M}_{0} / \tilde{\mathrm{P}}_{t}\right\}$, and, given initial real wealth $\mathrm{M}_{0} / \tilde{\mathrm{P}}_{0}+\tilde{q}_{0} \overline{\mathrm{k}}_{\text {, }}$ picks paths $\left\{\tilde{c}_{t}\right\},\left\{\tilde{m}_{t}\right\}$, and $\left\{\tilde{k}_{t}\right\}$ that maximize (1) subject to (2) and (3). Then $\left\{\tilde{\mathrm{p}}_{t}\right\}$ and $\left\{\tilde{\mathrm{q}}_{t}\right\}$ are perfect-foresight equilibrium paths if and only if for all $t \geq 0$,

$$
\begin{aligned}
& \tilde{c}_{t}=y+r \vec{k}, \\
& \tilde{m}_{t}=M_{t} / \tilde{P}_{t} .
\end{aligned}
$$

Condition (12) must hold in equilibrium because the balance of trade is necessarily zero when there is no capital mobility and the exchange rate floats. Thus, the economy is effectively closed from a macroeconomic standpoint. A consequence of (13) is that in perfect-foresight equilibrium, the path $\left\{\tilde{k}_{t}\right\}$ must satisfy

$$
\tilde{\mathrm{k}}_{\mathrm{t}}=\overline{\mathrm{k}}
$$

at each instant.

Differentiating (13), we obtain the relationship

$$
\dot{\mathrm{m}} / \mathrm{m}=\mu-\dot{\mathrm{P}} / \mathrm{P}
$$

linking desired real balances and the equilibrium price level. Combining (15) with (9) and (12) yields 


$$
\dot{\mathrm{m}}=[\mu+(r+\dot{q}) / q-x(y+r \bar{k}, m)] m, \quad x(c, m) \equiv u_{m}(c, m) / u_{c}(c, m)
$$

By (12), $\dot{\mathrm{c}}_{t}=0$ in equilibrium, and so, by differentiating (6) and equating the result to (8), we obtain

$$
\dot{m}=n^{-1}[\delta-(r+\dot{q}) / q] m, \quad n(m) \equiv \frac{m u_{c m}(y+r \bar{k}, m)}{u_{c}(y+r \bar{k}, m)} .
$$

Assuming $\eta \neq 1$, we may solve (16) and (17) for $\dot{m}$ and $\dot{q}$ to find the reduced-form equations of motion

$$
\begin{aligned}
& \dot{m}=\frac{[\mu+\delta-x(y+r \bar{k}, m)] m}{1+\eta} \\
& \dot{q}=\left[\delta-\frac{r}{q}-\frac{\eta}{1+\eta}(\mu+\delta-x(y+r \bar{k}, m))\right] q .
\end{aligned}
$$

Together, (18) and (19) characterize the collection of possible equilibrium paths for the economy.

The system described by (18) and (19) possesses a unique stationary state $(\vec{m}, \bar{q}), 6$ defined by the conditions

$$
\begin{aligned}
& u_{m}(y+r \bar{k}, \bar{m}) / u_{C}(y+r \bar{k}, \bar{m})=\mu+\delta, \\
& \bar{q}=r / \delta .
\end{aligned}
$$

Thus, in long-run equilibrium, the rate of return on capital must equal the subjective rate of time preference, while the marginal rate of substitution between consumption and real money services must equal the long-run opportunity cost of holding money. Any path converging to

\footnotetext{
6 Uniqueness of the stationary state is a consequence of the assumed normality of real money services.
} 
this stationary position is an equilibrium path, for in addition to satisfying the necessary conditions of optimality, it satisfies the transversality conditions

$$
\lim _{t \rightarrow \infty}\left[m_{t}+q_{t} k_{t}\right] \lambda_{t} e^{-\delta t}=0, \quad \lim _{t \rightarrow \infty} \lambda_{t} e^{-\delta t} \geq 0
$$

These ensure that the choices of consumption and real balances prevailing along a convergent path are optimal choices from the household's standpoint. 7

To examine the local uniqueness of equilibrium, we linearize the equations of motion around the stationary state, obtaining the approximate system

$$
\left[\begin{array}{c}
\dot{\mathrm{m}} \\
\dot{\mathrm{q}}
\end{array}\right]=\left[\begin{array}{cc}
\frac{-\overline{\mathrm{x}}_{\mathrm{m}} \overline{\mathrm{m}}}{1+\bar{n}} & 0 \\
\frac{-\bar{n} \overline{\mathrm{m}}_{\mathrm{m}} \overline{\mathrm{q}}}{1+\bar{\eta}} & \delta
\end{array}\right]\left[\begin{array}{l}
\mathrm{m}-\overline{\mathrm{m}} \\
q-\overline{\mathrm{q}}
\end{array}\right] .
$$

(Overbars denote stationary-state values.) A general solution of (22) takes the form

$$
\left[\begin{array}{l}
m_{t}-\bar{m} \\
q_{t}-\bar{q}
\end{array}\right]=\left[\begin{array}{ll}
\omega_{11} & \omega_{12} \\
\omega_{21} & \omega_{22}
\end{array}\right]\left[\begin{array}{l}
k_{1} \exp \left(\theta_{1} t\right) \\
k_{2} \exp \left(\theta_{2} t\right)
\end{array}\right],
$$

where $\theta_{1}=\delta$ and $\theta_{2}=\frac{-\bar{x}_{m} \bar{m}}{1+\bar{n}}$ are the characteristic roots of (22), $\left[\begin{array}{ll}\omega_{1 i} & \omega_{2 i}\end{array}\right]^{\prime}$ is an eigenvector belonging to $\theta_{i}(i=1,2)$, and $k_{1}$ and $k_{2}$ are arbitrary constants. As $\bar{x}_{m}=\left(\bar{u}_{c} \bar{u}_{m m}-\bar{u}_{m} \bar{u}_{c m}\right) / \bar{u}_{c}^{2}<0$ because real

${ }^{7}$ See Arrow and Kurz (1970). 


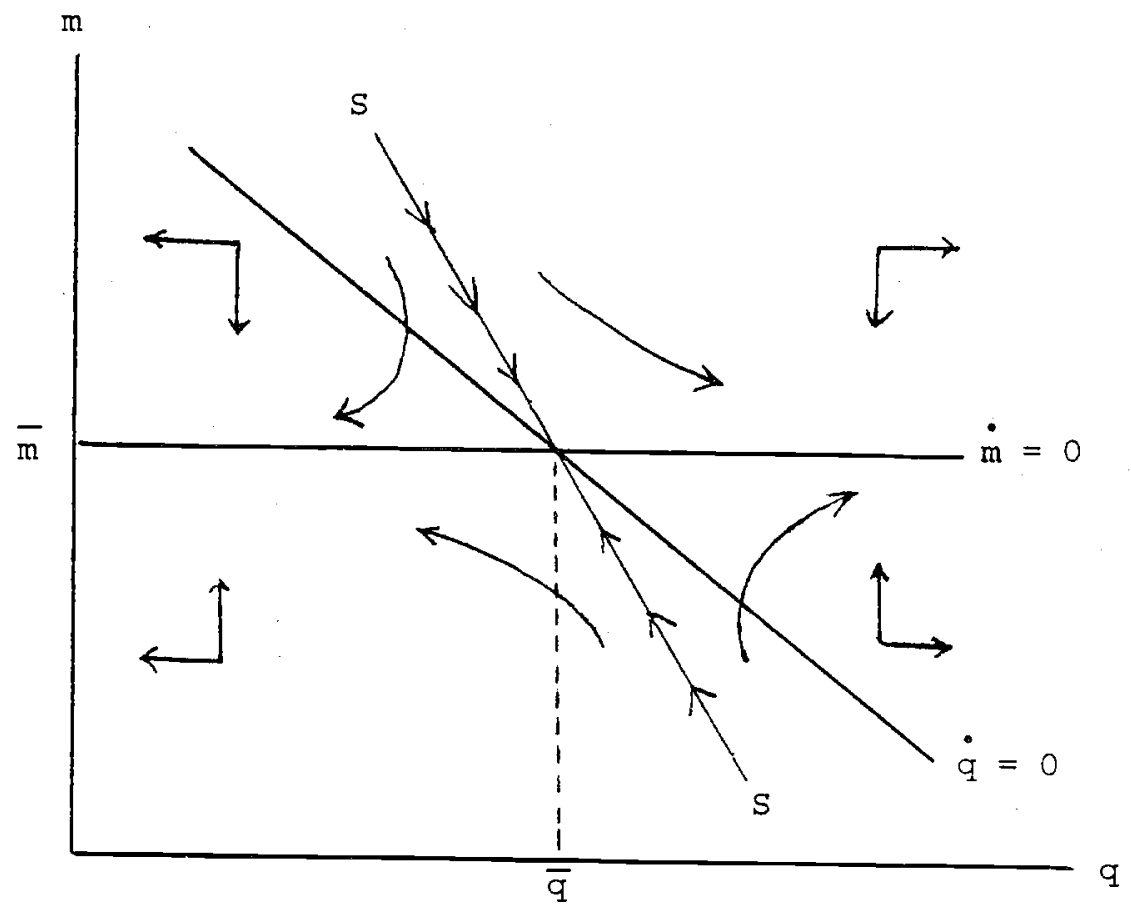

Figure 1 
balances are normal, $\theta_{2}$ is positive or negative according to whether

$$
\bar{\eta}=\frac{\overline{m u}_{\mathrm{cm}}}{\overline{\mathrm{u}}_{\mathrm{c}}} \gtrless-1 \text {. }
$$

When $\theta_{2}>0$, there is a unique "rational expectations" equilibrium path, namely, the stationary-state path $m_{t}=\bar{m}, q_{t}=\bar{q}$ obtained by imposing the initial conditions $k_{1}=k_{2}=0$ in (23). 8 A permanent, unanticipated $r i s e$ in the trend inflation rate $\mu$ causes the price level to jump immediately to its higher long-run value, but has no effect on the real interest rate, which remains at $r / \bar{q}=\delta$. Thus, there is no Mundell effect when the exchange rate floats and equilibrium is unique. Equilibrium will not be locally unique if $\theta_{2}<0$, however, for when this is so, any choice of the arbitrary constant $k_{2}$ yields a convergent solution to (22). Figure 1 displays the phase portrait of (22) when $\theta_{2}<0$. As $m$ and $q$ are both free to jump in response to unanticipated events, they may, at time $t=0$, assume any value along the locus ss in Figure 1. Each choice of initial position corresponds to a different perfect-foresight equilibrium path. Thus, the effects of disturbances are entirely indeterminate.

Brock (1975) has shown how multiple steady states may arise in a model similar to the present one when real balances are inferior over some ranges of income. Our example, however, shows that multiple equilibria may arise even though real balances are everywhere normal, so that there is a unique stationary position. For example, suppose the utility function is a member of the homothetic relative risk aversion family

\footnotetext{
The economy san attain this equilibrium because there are no predetermined variables. We ignore the possibility that there are non-convergent perfectforesight equilibrium paths.
} 


$$
u(c, m)=\left(c^{\alpha}{ }^{\beta}\right)^{1-R} /(1-R),
$$

where $\alpha+\beta \leq I$ and $R, \alpha, \beta>0$. Then $\eta=\beta(I-R)$ and rational-expectations equilibrium will fail to be unique whnever $R>(1+\beta) / \beta$.

The possibility of multiple equilibria in the present example is disturbing, for there are no obvious pathologies (as in the example of Blanchard (1979), where the income effect of changes in inflation dominates the substitution effect) and agents live forever. ${ }^{9}$ The problem is not a consequence of the presence of capital (our example "works" in the special case $\bar{k}=0$ ).. Indeed, when capital is introduced in the manner of Sidrauski (1967), so that the relative price of capital is fixed at $I$ by technological assumption, normality of both goods is sufficient to preclude the existence of multiple convergent equilibria (see Fischer (1979)). In an open economy facing a known path of foreign prices, the monetary authority can tie down the home price level by instantaneously pegging the exchange rate. This, as we shall see, removes the possiblility of multiple equilibria in the present model.

\section{Equilibrium and the Mundell Effect with a Pegged Exchange Rate}

The home country's central bank is now assumed to fix the exchange rate at each moment by accommodating any balance-of-payments disequilibrium through sales or purchases of non-interest-bearing foreign reserves. Because the central bank stands ready to exchange foreign for domestic money on given terms, the domestic price $P_{t}$ of the consumption good equals $E_{t} P_{t}^{*}$, where $E_{t}$ is the exchange rate (the price of foreign money in terms of domestic money) and $\mathrm{P}_{t}^{*}$ is the foreign-currency price of consumption. We suppose that the exchange rate is pegged at each instant, but allowed to crawl upward at the pre-announced, constant rate $\pi$. On the assumption that $P_{t}^{*}$ is fixed for all $t$, 9 It is the finiteness of agents' lifetimes that is behind the non-uniqueness examples discussed by Calvo (1978). 
$\pi=\dot{P} / P$, the (positive) domestic inflation rate. Government expenditure again consists entirely of transfer payments, determined now by the formula

$$
\tau_{t}=\pi m_{t}
$$

While (24) implies that government transfers compensate the public for the real depreciation of its money holdings, the rate of nominal money growth will not equal $\pi$ out of steady state. ${ }^{10}$

Under the present institutional assumptions, the future path of the price level is exogenously determined by the central bank, and the stock of real balances is thus a predetermined variable that can change only over time. The asset price $q_{t}$ is perfectiy flexible, however, and paths $\left\{\tilde{q}_{t}\right\}$ and $\left\{\tilde{\tau}_{t}\right\}$ define a perfect-foresight equilibrium if they induce choices $\left\{\tilde{c}_{t}\right\}$ and $\left\{\tilde{m}_{t}\right\}$ such that for all $t \geq 0$,

$$
\begin{aligned}
& \tilde{m}_{t}=\frac{M_{0}}{P_{0}}+{ }_{0}{ }^{t}\left[y+r \bar{k}-\tilde{c}_{s}\right] d s, \\
& \tilde{\tau}_{t}=\pi \tilde{m}_{t} .
\end{aligned}
$$

Condition (14) must again obtain in equilibrium.

$$
\text { Differentiation of the equilibrium condition (25) leads to the }
$$

differential equation

$$
\dot{\mathrm{m}}=\mathrm{y}+\mathrm{r} \overline{\mathrm{k}}-\mathrm{c}
$$

linking the equilibrium balance-of-payments surplus to the difference between national income and equilibrium absorption. Since $\dot{P} / \mathrm{P}=\pi$, (9) may be written in the form

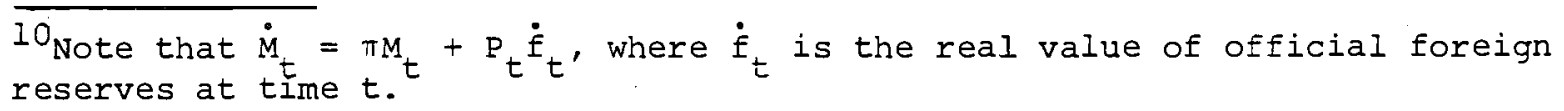




$$
\dot{q}=[x(c, m)-\pi-r / q] q
$$

Differentiating (6) and combining the result with (10) yields

$$
\dot{\mathrm{c}}=\frac{1}{\mathrm{u}_{\mathrm{CC}}}\left\{\mathrm{u}_{\mathrm{C}}[\delta-(r+\dot{\mathrm{q}}) / \mathrm{q}]-\mathrm{u}_{\mathrm{cm}} \dot{\mathrm{m}}\right\} \text {. }
$$

The foregoing expression, when combined with (26) and (27), gives the final equation of the system,

$$
\dot{c}=\frac{1}{u_{c c}}\left\{u_{c}[\delta+\pi-x(c, m)]-u_{c m}[y+r \bar{k}-c]\right\} .
$$

The stationary state $(\bar{c}, \bar{m}, \bar{q})$ of the system described by equations (26) - (28) is uniquely defined by (21) and

$$
\begin{aligned}
& \bar{c}=y+r \bar{k}, \\
& u_{m}(\bar{c}, \bar{m}) / u_{c}(\bar{c}, \bar{m})=\pi+\delta .
\end{aligned}
$$

In particular, $\bar{q}$ remains independent of the inflation rate. The transversality conditions cited above again ensure that any trajectory converging to the stationary state describes an equilibrium path. We now show that equilibrium is locally unique, in the sense that for any initial level of real balances $m_{0}$ sufficiently close to $\bar{m}$, there are unique values of consumption $c_{0}$ and the price of capital $q_{0}$ placing the economy on a convergent path. Thus, when the monetary authority pegs the exchange rate, the non-uniqueness problem that exists under a freely floating rate disappears.

The linear approximation to the system is

$$
\left[\begin{array}{c}
\dot{c} \\
\dot{m} \\
\dot{q}
\end{array}\right]=\left[\begin{array}{ccc}
\pi+\delta & -\frac{\bar{u}_{c} \bar{x}_{m}}{\bar{u}_{c c}} & 0 \\
-1 & 0 & 0 \\
\frac{r \bar{x}_{c}}{\delta} & \frac{r \bar{x}_{m}}{\delta} & \delta
\end{array}\right]\left[\begin{array}{c}
c-\bar{c} \\
m-\bar{m} \\
q-\bar{q}
\end{array}\right]
$$


A general solution takes the form

$$
\left[\begin{array}{c}
c_{t}-c \\
m_{t}-m \\
q_{t}-q
\end{array}\right]\left[\begin{array}{lll}
\omega_{11} & \omega_{12} & \omega_{13} \\
\omega_{21} & \omega_{22} & \omega_{23} \\
\omega_{31} & \omega_{32} & \omega_{33}
\end{array}\right]\left[\begin{array}{l}
k_{1} \exp \left(\theta_{1} t\right) \\
k_{2} \exp \left(\theta_{2} t\right) \\
k_{3} \exp \left(\theta_{3} t\right)
\end{array}\right]
$$

where the notation is the same as in the previous section. It is easily verified that the characteristic roots of (29) are

$$
\begin{aligned}
& \theta_{1}=\delta>0, \\
& \theta_{2}=\frac{\pi+\delta}{2}+\left[\frac{(\pi+\delta)^{2}}{2}+\frac{\bar{u}_{C m} \bar{x}_{m}}{\bar{u}_{C C}}\right]^{\frac{1}{2}}>0, \\
& \theta_{3}=\frac{\pi+\delta}{2}-\left[\frac{(\pi+\delta)^{2}}{2}+\frac{\bar{u}_{C} \bar{x}_{m}}{\overline{u_{C C}}}\right]^{\frac{1}{2}}<0 .
\end{aligned}
$$

The sign pattern implies that the rational-expectations equilibrium of the economy described by (29) is unique. Given an initial value $m_{0}$ of the predetermined variable, the solution obtained from (30) by setting $k_{1}=k_{2}=0$ and $k_{3}=\left(m_{0}-\bar{m}\right) / w_{23}$ is the unique convergent solution of (29) satisfying the initial condition on real balances. It follows that the initial values of consumption and the price of capital are unambiguously determined.

With the local uniquenss of equilibrium established, it makes sense to ask whether an unanticipated, permanent increase in the inflation rate $\pi$ leads to a short-run decline in the real rate of interest if the economy is initially at rest. To answer this question, we must look more closely at 
the unique saddlepath converging to the economy's long-run equilibrium. Differentiating (30) and imposing the initial conditions $k_{1}=k_{2}=0$, we find that

$$
\begin{aligned}
& \dot{c}_{t}=\theta_{3}\left(c_{t}-\bar{c}\right), \\
& \dot{m}_{t}=\theta_{3}\left(\omega_{23} / \omega_{13}\right)\left(c_{t}-\bar{c}\right), \\
& \dot{q}_{t}=\theta_{3}\left(\omega_{33} / \omega_{13}\right)\left(c_{t}-\bar{c}\right)
\end{aligned}
$$

along the convergent saddlepath. From (29) (or directly, from (26)), $\omega_{23} / \omega_{13}=-1 / \theta_{3}>0$, and so consumption and real balances must rise or fall simultaneously along the saddlepath.

As in Calvo (1981), a rise in $\pi$ occasions a fall in long-run real balances; and because consumption and real balances fall together along the saddlepath, consumption must rise in the short run (if the economy is initially at a stationary position) so that it may eventually return to its inflation-invariant long-run level, $y+r \bar{k}$. The effect of inflation on real interest clearly hinges on the sign of $\omega_{33} / \omega_{13}$. If this ratio is positive, $c$ and $q$ must fall together on the transition path following a rise in $\pi$. And if the economy is initially at long-run equilibrium, $q$ must rise on impact if it is to regain its long-run value $r / \delta$. The Mundell effect is verified in this case, for if $q$ rises and $\dot{q}$ falls in the short run, the real rate of interest, $(r+\dot{q}) / q$, must fall. We now establish the existence of a Mundell effect in the present model by showing that $\omega_{33} / \omega_{13}$ must indeed be strictly positive. From (29), we find that

$$
\omega_{33} / \omega_{13}=\left(\theta_{3} r \vec{x}_{c}-r \bar{x}_{m}\right) / \theta_{3} \delta\left(\theta_{3}-\delta\right) .
$$


Recalling that $\overline{\mathrm{x}}_{C}=\left(\overline{\mathrm{u}}_{C} \overline{\mathrm{u}}_{C \mathrm{~m}}-\overline{\mathrm{u}}_{\mathrm{m}} \overline{\mathrm{u}}_{C C}\right) / \overline{\mathrm{u}}_{C}^{2}>0$ when consumption is a normal good, it can be established, after some manipulation, that the right-hand side of (3I) has the same sign as

$$
\overline{\mathrm{u}}_{\mathrm{CC}} \overline{\mathrm{u}}_{\mathrm{mm}}-\left(\overline{\mathrm{u}}_{\mathrm{Cm}}\right)^{2}
$$

But expression (32) is strictly positive because the utility function is concave. It follows that $\omega_{33} / \omega_{13}>0$, implying that a permanent increase in the expected inflation rate must depress the real rate of incerest in the short run.

\section{Conclusion}

This paper has studied the link between inflation and real interest in a simple model based on individual utility maximization over time. When the exchange-rate follows an exogenous path determined by the central bank, so that the domestic price level and stock of real balances are instantaneously rigid, an increase in expected inflation does depress the real interest rate in the short run if the economy is initially at rest. The fall in real interest, together with the concomitant rise in consumption, maintains the necessary equality between the marginal utility of money and the opportunity cost, in utility terms, of holding real balances. When the exchange rate floats and the price level is accordingly flexible, real balances drop immediately in response to increased inflation, restoring portfolio balance with no change in consumption or real interest. It may occur, however, that the model's equilibrium is not uniquely determined in the flexible-price case. Surprisingly, non-uniqueness can occur in quite unexceptional circumstances. It does not presuppose any 
of the pathological conditions typically invoked to generate economies with multiple rational-expectations equilibria.

The paper has drawn heavily on work of Brock (1975) and Calvo (1981), introducing into their monetary models an additional asset, non-depreciating, non-reproducible capital. An obvious next step is to extend the present work to a two-sector setting in which investment goods can be produced while the price of capital in terms of consumption remains variable. 


\section{$\underline{\text { References }}$}

Arrow, K.J. and M. Kurz, 1970, Public investment, the rate of return, and optimal fiscal policy (The Johns Hopkins Press, Baltimore, MD).

Blanchard, 0.J., 1979, Backward and forward solutions for economies with rational expectations, American Economic Review Papers and Proceedings, $69,114-118$

Brock, W.A., 1972, Money and growth: The case of Iong run perfect foresight, mimeo, University of Chicago.

Brock, W.A., 1975, A simple perfect foresight monetary model, Journal of Monetary Economics, 1, 133-150.

Calvo, G.A., 1975, On models of money and perfect foresight, Discussion Paper No. 74-7518, Columbia University.

Calvo, G.A., 1978, On the indeterminacy of interest rates and wages with perfect foresight, Journal of Economic Theory, 19, 321-337.

Calvo, G.A., 1979, An essay on the managed float--the small country case, Discussion Paper No. 24, Columbia University.

Calvo, G.A., 1981, Devaluation: Levels vs. rates, Journal of International Economics, 11, forthcoming.

Cumby, R.E., 1979, Monetary policy under dual exchange rates, mimeo, Massachusetts Institute of Technology.

Fischer, S., 1979, Capital accumulation on the transition path in a monetary optimizing model, Econometrica, 47, 1433-1440.

Metzler, L.A., 1951, Wealth, saving, and the rate of interest, Journal of Political Economy, 59, 93-116.

Mundell, R.A., 1963, Inflation and real interest, Journal of Political Economy, 71, 280-283

Sidrauski, M., 1967, Rational choice and patterns of growth in a monetary economy, American Economic Review Papers and Proceedings, 57, 534-544. 
Proof that sign $\left(\omega, \omega^{\omega}\right)=\operatorname{sign}\left(u_{c c} u_{m m}-\left(u_{c m}\right)^{2}\right)$

Note that

$$
\theta_{3}=\frac{1}{2} \frac{u_{m}}{u_{c}}-\sqrt{\frac{1}{4}\left(\frac{u_{m}}{u_{c}}\right)^{2}+\frac{u_{c} u_{m m}-u_{m} u_{c m}}{u_{C} u_{c c}}}
$$

(overbars are omitted), for

$$
x_{c}=\frac{u_{c} u_{c m}-u_{m} u_{c c}}{u_{c}^{2}}>0 \text {. }
$$

Also

$$
\begin{aligned}
& x_{m}=\frac{u_{c} u_{m m}-u_{m} u_{c m}}{u_{c}^{2}}<0 . \quad \text { clearly (31) is positive if and only if }
\end{aligned}
$$

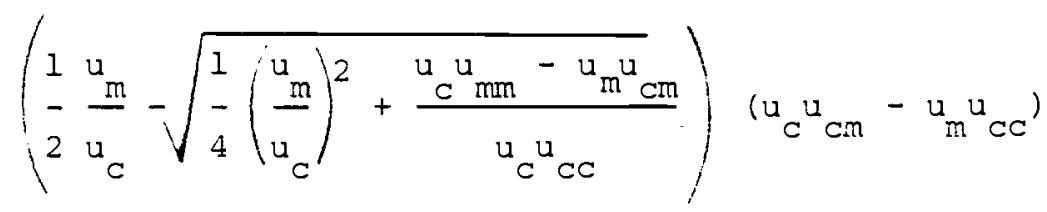

$$
\begin{aligned}
& >u_{C} u_{m m}-u_{m} u_{c m}
\end{aligned}
$$

i.e., iff

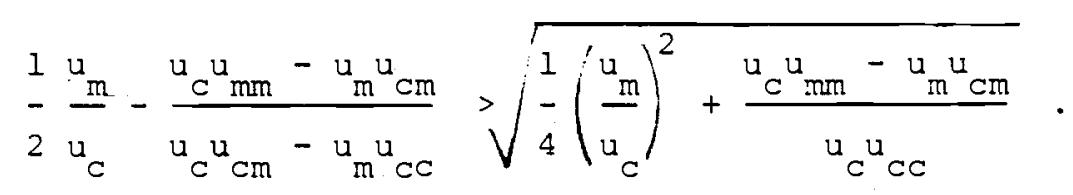

Squaring both sides of the foregoing, we see that (*) holds iff

$$
\begin{aligned}
& -\frac{u_{m}}{u_{C}}\left(\frac{u_{C} u_{m m}-u_{m} u_{c m}}{u_{C} u_{c m}-u_{m} u_{C C}}\right)+\left(\frac{u_{C} u_{m m}-u_{m} u_{c m}}{u_{C} u_{c m}-u_{m} u_{C C}}\right)^{2} \\
& >\frac{u_{C} u_{m m}-u_{m} u_{c m}}{u_{C} u_{c c}} .
\end{aligned}
$$


Now, $(* *)$ is equivalent to

$$
\begin{aligned}
& \left(\frac{u_{c m m} u_{m}-u_{m} u_{c m}}{u_{c} u_{c m}-u_{m} u_{c c}}\right)^{2}>\left(u_{c} u_{m m}-u_{m} u_{c m}\right)\left(\frac{1}{u_{c} u_{c c}}+\frac{u_{m}}{u_{c}\left(u_{c} u_{c m}-u_{m} u_{c c}\right)}\right) . \\
& =\frac{\left(u_{c} u_{m m}-u_{m} u_{c m}\right)}{u_{C}}\left(\frac{u_{C} u_{c m}}{u_{c C}\left(u_{C} u_{c m}-u_{m} u_{C C}\right)}\right)
\end{aligned}
$$

which holds iff

$$
\frac{u_{c m m} u_{m}-u_{m} u_{c m}}{u_{C} u_{c m}-u_{m} u_{c c}}<\frac{u_{c m}}{u_{c c}} .
$$

Manipulation of this last inequality shows that it is valid iff

$$
u_{c c} u_{m m}-\left(u_{c m}\right)^{2}>0
$$

